San Jose State University

SJSU ScholarWorks

Master's Theses

Master's Theses and Graduate Research

Spring 2015

\title{
Examination of Employee Alignment as a Predictor of Work Engagement
}

Troy Stephen Pasion-Caiani

San Jose State University

Follow this and additional works at: https://scholarworks.sjsu.edu/etd_theses

\section{Recommended Citation}

Pasion-Caiani, Troy Stephen, "Examination of Employee Alignment as a Predictor of Work Engagement" (2015). Master's Theses. 4554.

DOI: https://doi.org/10.31979/etd.ydep-ks65

https://scholarworks.sjsu.edu/etd_theses/4554

This Thesis is brought to you for free and open access by the Master's Theses and Graduate Research at SJSU ScholarWorks. It has been accepted for inclusion in Master's Theses by an authorized administrator of SJSU ScholarWorks. For more information, please contact scholarworks@sjsu.edu. 


\title{
EXAMINATION OF EMPLOYEE ALIGNMENT AS A PREDICTOR OF WORK ENGAGEMENT
}

\author{
A Thesis \\ Presented to \\ The Faculty of the Department of Psychology \\ San José State University \\ In Partial Fulfillment \\ of the Requirements for the Degree \\ Master of Science \\ by \\ Troy Pasion-Caiani
}

December 2014 
(C) 2014

Troy Pasion-Caiani ALL RIGHTS RESERVED 
The Designated Thesis Committee Approves the Thesis Titled

EXAMINATION OF EMPLOYEE ALIGNMENT AS A PREDICTOR OF WORK ENGAGEMENT

by

Troy Pasion-Caiani

\title{
APPROVED FOR THE DEPARTMENT OF PSYCHOLOGY \\ SAN JOSE STATE UNIVERSITY
}

December 2014

\begin{abstract}
Dr. Megumi Hosoda Department of Psychology
Dr. Howard Tokunaga Department of Psychology

Dr. B. Lynn Ware Integral Talent Systems, Inc.
\end{abstract}




\title{
ABSTRACT \\ EXAMINATION OF EMPLOYEE ALIGNMENT AS A PREDICTOR OF WORK ENGAGEMENT
}

\author{
By Troy Pasion-Caiani
}

Work engagement, which is defined as a positive affective-motivational state of fulfillment in workers, characterized by vigor, dedication, and absorption in a work role, has been shown to produce many benefits for both individuals and organizations. In the present study, employee alignment was introduced as an additional personal resource measuring employees' attitudes and beliefs toward their organization, their leaders, and the mission, vision, and goals of their organization. Using a sample of 1,510 employees, this study examined perceived organizational support (POS), supportive leader behavior, and employee alignment as predictors of work engagement. Furthermore, this study tested the incremental validity of employee alignment in predicting work engagement above and beyond POS and supportive leader behavior. It was found that POS, supportive leader behavior, and employee alignment all positively predicted work engagement. Additionally, employee alignment was shown to have additive predictive validity above and beyond POS and supportive leader behavior. These findings suggest that if workers believe in their organization's mission, vision, goals, leaders, and direction of the company, they are more likely to become engaged in their work role above and beyond perceived organizational support and supportive leader behaviors. Organizational strategies to increase work engagement through POS, supportive leader behavior, and employee alignment are suggested. 


\section{ACKNOWLEDGEMENTS}

My achievements in graduate school are a testimony to all the support, love, and direction from people around me who cared enough to place their vote of confidence in me, be there through hardships, and challenged me to push myself and accomplish a postgraduate education.

I wouldn't have been able to succeed without the unconditional love and support of my dad, mom, and brothers. Thank you for always being there for me when I needed you and understanding when I needed space to grow on my own. This achievement begins what my father coined the Pasion-Caiani family cycle of education.

A huge thank you to my advising committee. I wouldn't have been able to complete this thesis without your direction. Lynn, thank you so much for being the best mentor and boss I've ever had in my life. I owe so much of my professional development to you and your guidance. Megumi, I appreciate you being my chair because you provided the right amount of feedback and collaboration. Thank you for your patience during the revision process... it was definitely a task! Throughout my entire graduate school experience you always played the role of surrogate mother and guiding light. Your laugh always brightened my day and your coaching spurred me to become more educated. Howard, you are the best statistics professor I have ever had. I'm very grateful for your engaging teaching ability because during your lectures there was never a dull moment. Again, thank you all who have touched my life and believed in me during this journey through graduate school. My success is a testament to your greatness. 


\section{TABLE OF CONTENTS}

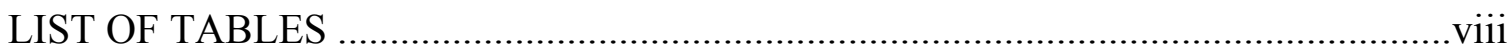

INTRODUCTION

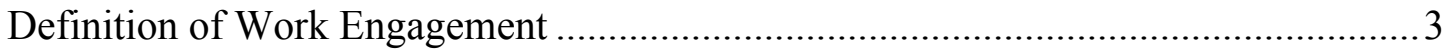

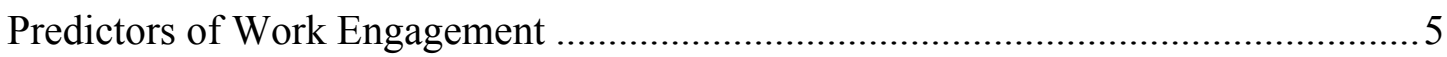

Perceived Organizational Support (POS) ......................................................... 6

Supportive Leader Behavior ....................................................................

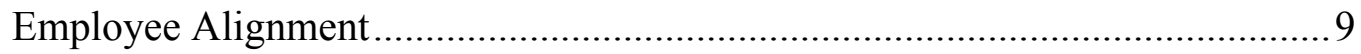

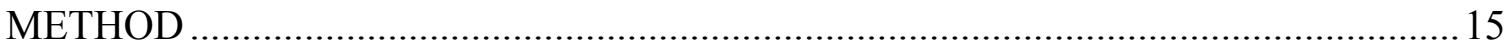

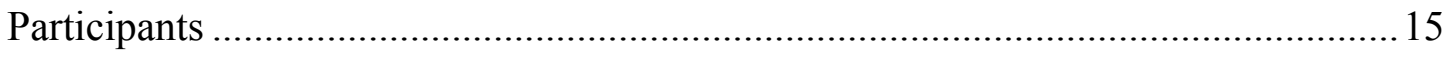

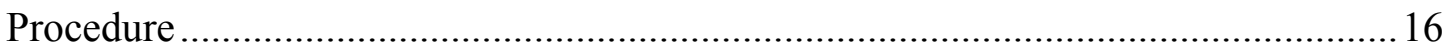

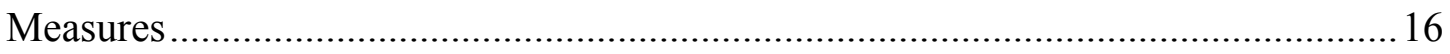

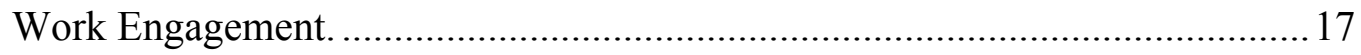

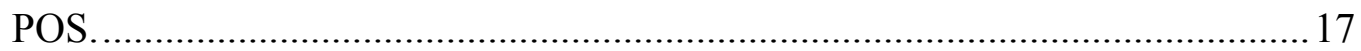

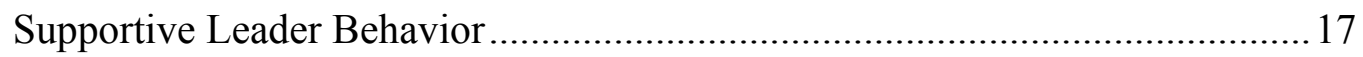

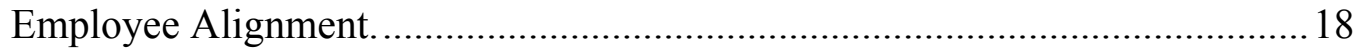

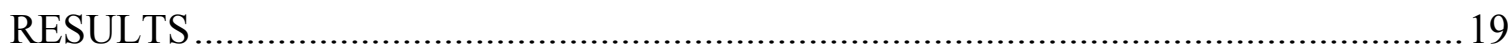

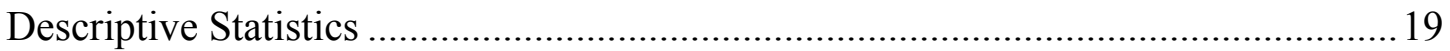

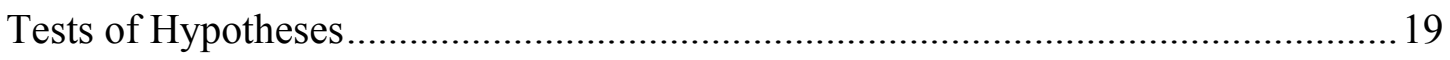

Research Question ............................................................................................ 21

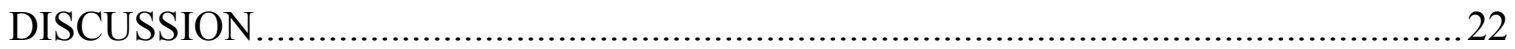


Theoretical Implications of the Present Study

Practical Implications of the Present Study ............................................................2 24

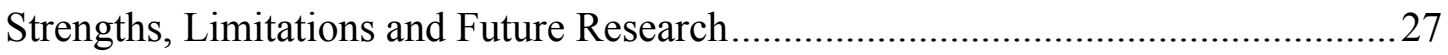

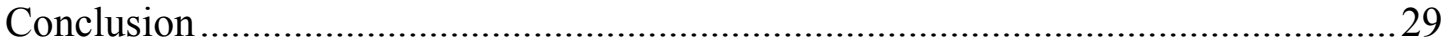

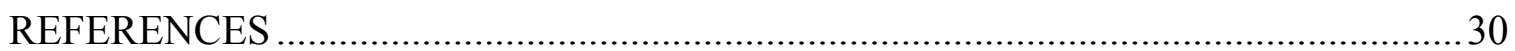




\section{LIST OF TABLES}

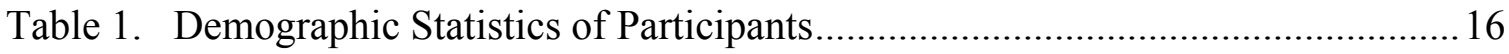

Table 2. Descriptive Statistics and Correlations............................................................ 19

Table 3. Standard Multiple Regression Analysis Results …………………………......2 20

Table 4. Hierarchical Regression Analyses ..................................................................... 21 


\section{Introduction}

Researchers have paid a considerable amount of attention to work engagement over the past two and a half decades to better understand its antecedents and consequences. Work engagement is defined as a positive affective-motivational state of fulfillment in workers, characterized by vigor, dedication, and absorption in a work role (Kahn, 1990; Schaufeli \& Bakker, 2004). Work engagement has been shown to be linked to positive organizational and employee outcomes (Hakanen \& Schaufeli, 2012; Kataria, Rastogi, \& Garg, 2013). For example, work engagement is associated with increased profitability, and sales growth, as well as improved customer satisfaction and loyalty (Roberts \& Davenport, 2002; Schneider, Macey, Barbera \& Nigel, 2009). Work engagement is also positively related to employees' task performance, innovative behavior, and mental and physical health, and negatively related to their intentions to leave the company (Bakker, 2011; Christian, Garza, \& Slaughter, 2011; Hakanen \& Schaufeli, 2012; Rich, Lepine, \& Crawford, 2010; Saks, 2006; Shuck, Reio, \& Rocco, 2011). Furthermore, when an individual team member is engaged at work, engagement becomes contagious to other team members, resulting in increased engagement in a team (Bakker, Van Emmerik \& Euwema, 2006; Bakker \& Xanthopoulou, 2009).

Consequently, work engagement is likely to lead to organizational effectiveness through optimal employee performance as well as increased worker well-being. Because work engagement has been shown to be related to many positive outcomes, researchers have been examining factors that predict work engagement, including job resources and 
personal resources (e.g., supervisor support, self-efficacy) (Freeney \& Fellenez, 2013; Xanthopoulou, Bakker, Demerouti, \& Schaufeli, 2007, 2009).

Various job resources have been proposed to predict work engagement (Christian et al., 2011). Job resources include job characteristics (e.g., perceived organizational support, autonomy, task variety, task significance, feedback, organizational climate, coworker support) and supportive leader behavior (e.g., supervisor support, clear expectations, trust, transformational leadership) (Christian et al., 2011; Freeney \& Fellenez, 2013; Halbesleben, 2010; Rich et al., 2010; Saks, 2006). Work environments that provide many resources are likely to promote employees' willingness to dedicate their efforts and abilities to the task, because employees with such resources will complete a task successfully and attain work goals (Bakker, 2011).

In addition to job resources, more recent research attention has been given to examine personal resources as predictors of work engagement (Hobfoll, Johnson, Ennis, \& Jackson, 2003). Personal resources are positive self-evaluations that are linked to resiliency and refer to the sense of the ability of individuals to control their environment (Hobfoll et al., 2003). Personal resources include personality traits and state-like characteristics. Examples of personal resources are self-efficacy, organizational-based self-esteem, and optimism (Xanthopoulou et al., 2007, 2009). Luthans, Norman, Avolio, and Avey (2008) argue that engaged workers appear to be different from other workers because they possess particular personal resources, which seem to empower them to be able to control and impact their work environment. Therefore, in addition to job resources, personal resources seem to be important predictors of work engagement. 
However, compared to research on job resources, research on personal resources as predictors of work engagements is scarce. More research attention should be paid to examining additional personal resources as predictors of work engagement.

Employee alignment is hypothesized as a personal resource in this study. Employee alignment is defined as the degree to which employees value and believe in the goals, mission, and vision of their organization (Ware, 1999). When employees value and believe in organizational goals and see how their work contributes to their company's values and goals, this might foster a sense of meaningfulness and purpose in their work role. Consequently, they might become more engaged with their work. This assertion is reasonable given Kahn's (1990) definition of engagement as a work situation where employees find work meaningful. However, little study has examined employee alignment as a predictor of work engagement.

The investigation of employee alignment as a predictor of work engagement is important because if employee alignment predicts work engagement, personal resources could include not only personality traits but also an attitudinal variable. Companies could provide onboarding and training programs to increase employment alignment as well as select those who have the same values as the organization. Therefore, the primary purpose of this study was to examine whether employee alignment predicts work engagement and whether it predicts work engagement above and beyond more frequently studied job resources (i.e., perceived organizational support and supportive leader behavior). The following sections present the definition of work engagement, followed by a review of literature on the predictors of work engagement, the introduction of 
employee alignment as a personal resource, and finally the hypotheses tested in this study.

\section{Definition of Work Engagement}

Work engagement is defined as an employee's positive affective-motivational state of fulfillment characterized by being energized, absorbed, and identified with one's work role (Kahn, 1990; Maslach, Schaufeli, \& Leiter, 2001). Kahn defined personal engagement as the harnessing of organizational members' selves to their work roles; engaged individuals express themselves physically, cognitively, and emotionally during role performance. That is, people become physically involved in tasks, cognitively vigilant, and emotionally connected to others (Kahn, 1990).

Work engagement reflects the personal energy and investment employees bring to their work. Maslach et al. (2012) argue that work engagement consists of three dimensions: vigor, dedication, and absorption. Vigor is characterized as high levels of energy and mental resilience at work and the willingness to invest effort into one's work and being persistent in the face of difficulties. Dedication is defined as strong identification with one's work characterized by a sense of significance, enthusiasm, inspiration, and pride. Absorption is a positive psychological state of total immersion and concentration on one's work; as a result, detaching from work is difficult because time passes quickly.

According to Kahn (1990), psychological conditions that influence work engagement include meaningfulness, safety, and availability. Psychological meaningfulness is experienced when workers feel that they have had a return on their 
investment of physical, cognitive, or emotional energy. Kahn describes psychological safety as workers' feeling comfortable expressing their authentic self in a work role without fear of negative repercussions to their self-image, status, or career.

Psychological availability refers to the capacity of the individual to invest resources into the work role (Kahn, 1990).

When the psychological conditions that foster work engagement are part of the work environment, workers display vigor, dedication, and absorption. Engaged employees not only have the capacity to be energetic, but they also enthusiastically apply this energy to their work. Engaged workers feel compelled to strive toward a challenging goal and accept a personal commitment to attain the goal. Employees who are engaged are intensely involved and become absorbed in their work, lose track of time and have a diminished response to distractions (Bakker, 2011).

\section{Predictors of Work Engagement}

Job resources in the job demands-resources (JD-R) model (Bakker \& Demerouti, 2008) have been studied as predictors of work engagement. Job resources refer to physical, psychological, social, or organizational aspects of the job that are functional in achieving work goals, reduce job demands and the associated physiological and psychological costs, and stimulate personal growth, learning, and development (Bakker \& Demerouti, 2007; Schaufeli \& Bakker, 2004). Examples of job resources include perceived organizational support (POS), autonomy/job control, social support from supervisor and co-workers, task significance, task variety, growth opportunities, 
performance feedback/recognition, and supervisory support/coaching (Christian et al., 2011; Freeney \& Fellenez, 2013; Halbesleben, 2010; Rich et al., 2010; Saks, 2006). Job resources are thought to increase work engagement because they play both an intrinsic and an extrinsic motivational role (Bakker \& Demerouti, 2007, 2008). Job resources play an intrinsically motivating role because they foster employees' growth, learning, and development, and fulfill basic human needs such as the needs for autonomy, relatedness, and competence. For instance, a supportive leader who provides proper feedback fosters individual learning, which increases job competence. Likewise, allowing employees more control is likely to satisfy the need for autonomy, and social support from the leader or co-workers satisfies the need to belong. Job resources also play an extrinsic motivational role because they are influential in achieving work goals. In a work environment where social support is provided in the form of feedback, advice, and recognition, employees should be more willing to invest their energies toward achieving goals. For example, Kahn's (1990) research findings indicate that workers were more engaged when they had rewarding interactions with coworkers.

Job resources have been consistently found to be predictors of work engagement (Christian et al., 2011; Halbesleben, 2010; Mauno, Kinnunen, Mäkikangas, \& Feldt, 2010). For example, a meta-analysis by Halbesleben (2010) showed that there was a positive overall relationship between job resources and work engagement. A metaanalysis by Christian, Garza, and Slaughter (2011) also showed positive correlations between various job resources and work engagement; resources such as task variety and task significance had strong relationships with work engagement, and autonomy/control, 
feedback, social support, and leader-member exchange had moderately strong relationships with work engagement. As a result of these findings, the current study examined POS and supportive leader behavior as job resources predicting work engagement; this is because if a worker perceives their company supports them then their perceptions are reinforced by supportive leaders, workers may be more likely to become engaged in their work role (Eisenberger, Stinglhamber, Vandenberghe, Sucharski, \& Rhoades, 2002; Kahn, 1990).

Perceived organizational support (POS). POS is defined as employees' general belief that their organization values their contributions and considers their well-being (Rhoades \& Eisenberger, 2002). Employees personify the organization and take its favorable treatment or unfavorable treatment as an indication that the organization favors or disfavors them (Rhoades \& Eisenberger, 2002). POS fulfills social-emotional needs of employees in the workplace such as the need for esteem (e.g., superior performance), affiliation (e.g., organization is committed to the worker), and emotional support (e.g., organization provides understanding and material aides for work/non-work related needs). POS also fulfills the performance-reward expectancy that employees expect that their increased positive organizational behavior will be recognized and rewarded (Rhoades \& Eisenberger, 2002). POS evokes the norm of reciprocity and produces a felt obligation to reciprocate (Rhoades \& Eisenberger, 2002). Thus, when employees believe that their organization values their contributions and cares about their well-being, they feel obligated to repay the organization and act in ways that benefit the organization and achieve its goals (Eisenberger \& Stinglhamber, 2011). One way to reciprocate the 
organization's support might be to engage in one's work. Furthermore, POS could be influenced by employees' interactions with "agents" of the organization such as managers and supervisors, and positive interactions with them influence employees' perceptions of a "safe" work environment that affects their willingness to invest themselves and become engaged (Eisenberger et al., 2002; Kahn, 1990).

Consistent with the above argument, Rich, Lepine, and Crawford (2010) demonstrated that the firefighters reported higher levels of work engagement when they experienced higher levels of POS. Saks (2006) also found that POS predicted work engagement. Given these findings, the following hypothesis was tested.

Hypothesis 1: POS will predict work engagement positively.

Supportive leader behavior. Supportive leader behavior includes leaders' actions that support employees in their goal achievement. Supportive leader behavior is a social variable that predicts employee engagement (Freeney \& Fellenez, 2013). The role of managers as a social resource has been emphasized as an important variable to enhance work engagement (Freeney \& Fellenez, 2013; Mauno et al., 2010). Examples of supportive leader behaviors that are effective in stimulating engagement are providing recognition, coaching, and feedback, as well as giving some control to their subordinates to increase their perceptions of autonomy (Bakker \& Bal, 2010; Christian et al., 2011; Vassos, Nankervis, Skerry, \& Lante, 2013; Xanthopoulou, Bakker, Demerouti \& Schaufeli, 2009). Managers effectively or ineffectively interact with employees, and such interactions might influence employees' perceptions of the work environment (Eisenberger, Stinglhamber, Vandenberghe, Sucharski, \& Rhoades, 2002). It should be 
noted that although supportive leader behavior seems to be related to POS, there is a distinction between the two (Kottke \& Sharafinkski, 1988; Shore \& Tetrick, 1991). POS conceptually measures the way people are affected by the structure of the organizational systems such as the way the organization is designed, policy and procedures, senior management, organizational rewards, and job conditions (Eisenberger et al., 2002). In contrast, supportive leader behavior considers the social context and mainly deal with the interaction between individual(s) and supervisor (Kast \& Rosenzweig, 1979). Consequently, POS and supportive leader behavior are treated as separate predictors of work engagement.

Supportive leader behaviors are likely to foster trust and confidence in employees, which is likely to create a sense of a safe work environment for them. In such an environment, employees might feel being able to show and employ their selves without feeling negative consequences to their self-images (Kahn, 1990). Such supportive leader behaviors are likely to allow their subordinates to invest more of themselves into their work role, and consequently they become engaged with their work (Deci, Connell, \& Ryan, 1989; Edmondson, 1999; Kahn, 1990; May, Gilson, \& Harter, 2004; Oldham \& Cummings, 1996).

There is indirect evidence that supportive leader behaviors are likely to be positively related to employee's work engagement. For example, Freeney and Fellenez (2013), studying midwife nurses in understaffed maternity hospitals, found that perceived supervisor support, along with other social/relational job resources (e.g., social support from peers, autonomy), explained $52 \%$ of the variance in work engagement. These 
results highlight the importance of perceived supervisor support on predicting work engagement. These findings emphasize the importance of the social/relational characteristics of perceived supervisor support as a job resource in predicting employee engagement. Supportive leader behavior is similar to perceived supervisor support. Supportive leader behavior is defined as the actions of managers such as supervisor support and encouraging a creative team environment, which are instrumental in influencing employees' perceptions regarding support. Thus, the following hypothesis was tested.

\section{Hypothesis 2: Supportive leader behavior will predict work engagement} positively.

As mentioned earlier, recent studies have focused on personal resources as predictors of work engagement. Personal resources are positive self-evaluations that are linked to resiliency and refer to the sense of the ability of individuals to control their environment (Hobfoll et al., 2003). Consistent with job recourses, personal resources are functional in achieving work goals; they reduce job demands and the associated physiological and psychological costs, and stimulate personal growth, learning, and development. Examples of personal resources include personality traits such as selfefficacy, organizational-based self-esteem, and optimism (Xanthopoulou et al., 2007, 2009). Although research on the relationship between personal resources and work engagement seems to focus on personality traits as personal resources, the present study introduces employee alignment as an additional personal resource and a predictor of work 
engagement. The following section provides a definition of employee alignment and explains how it will be related to work engagement.

Employee alignment. Employee alignment refers to the degree to which workers value and believe in the organization's goals and mission, and devote time working toward organizational goals (Ware, 1999). In other words, actions taken by employees to achieve results are aligned with the business's mission and goals, with employees developing a sense of meaning and purpose in their work role and identifying themselves with their work (Kahn, 1990; May et al., 2004; Fairlie, 2011; Spreitzer, Kizilos, \& Nason, 1997). For example, employees whose values are aligned with those of the organization would be highly motivated toward the mission of the organization and be passionate in their work role because of their perceptions that they are making a difference (Ware, 1999).

As with job resources, personal resources serve two motivational roles: intrinsic and extrinsic. Employee alignment might serve as an intrinsic motivational role because workers are likely to internalize the goals, mission, and vision of the organization, and their work and goal achievement is conducive to personal growth because it builds a sense of self-esteem and self-efficacy (Christian et al., 2011). Employee alignment is also like to serve as an extrinsic motivational role because employee alignment is likely to reduce role ambiguity. This is because organizational goals are explicitly delineated to employees that assimilate them into the role they play in accomplishing the organization's most critical goals (Lorente, Salanova, Martinez, \& Schaufeli, 2008). 
Employee alignment is defined as a personal resource with the following conceptual reasoning. Employee alignment is the aligning of personal values and beliefs that stem from the employee's idea of "self" with the organizational goals, mission, and vision; thus, identifying their meaningful work role as an extension of their "ideal self" (Chalofsky \& Krishna, 2009; May et al., 2004). The ideal self is described as a positive self-concept, the way a person views his or her self-image and/or the potential of whom he or she may become, as well as the way a person consciously wishes to be perceived by others (Chalofsky \& Krishna, 2009). Kahn $(1990,1992)$ proposed when employees are able to use their preferred selves at work, they will become more engaged; as a result, they utilize the fullest of their capabilities and excel in the work role. Therefore, employee alignment may be considered an additional antecedent of work engagement because an employee who is aligned shares the vision and mission of the organization, and is clear regarding what is expected of his or her role as well as the way his or her role impacts the organization's bottom line, which creates a sense of meaningfulness in his or her work role, all of which contribute to work engagement.

Employee alignment is conceptualized as a personal resource driven by meaningfulness. According to Kahn (1992) and May et al. (2004), work engagement is conceptualized as investment of the complete self or "human spirit" into the work role with a prerequisite being psychological meaningfulness. People have a primary need to seek meaning in the work they invest time and energy into. May et al. studied psychological conditions affecting employee's engagement (meaningfulness, safety, and availability) and found that out of the three conditions, psychological meaningfulness had 
the strongest positive relationship with work engagement. Therefore, meaningfulness conceptualized as an integral part of employee alignment is expected to produce similar positive predictive results with work engagement. Meaningful work is important because purpose in the work role creates deep intrinsic motivation and attachment to one's work as well as humanistic and practical reasons such as personal fulfillment, personal growth, and personal investment of energy (Chalofsky \& Krishna, 2009; Spreitzer et al., 1997). Therefore, meaningfulness of a role is motivating due to the sense of aligned goals between the individual and the organization.

In addition to meaningfulness, psychological safety is another key conceptual component of employee alignment. Echoing the thought process of Kahn (1990), a reoccurring theme emerges in the predictors of work engagement literature, which is trust (Bargagliotti, 2012; Havens, Warshawsky, \& Vasey, 2013; Kahn; Macey \& Schneider, 2008). Kahn described the concept of trust as psychological safety in an environment that influences an individual's willingness to invest into his or her work role (May et al., 2004). Psychological safety refers to a worker's feeling comfortable in expressing his or her authentic self in a work role without fear of negative consequences to his or her selfimage, status, or career. Consequently, for employees to be engaged, they need to feel safe based on confidence in the direction that the company is headed and expect that the work they do is meaningful because the effort is directed at achieving organizational goals (employee alignment). Psychological safety, operationalized as trust, may be the underlying phenomenon in employee alignment as well as most other predictors of engagement. 
Employee alignment is operationalized as the attitudes and beliefs of workers toward organizational goals, mission, and vision as well as measuring his or her trust and confidence in the organization and its leaders, which distinguish employee alignment from the comparable construct of value congruence. Although employment alignment is similar to the concept of value congruence, which is defined as the concordance between personal values and organizational values, the fundamental difference between the two is the concept of trust (Caldwell, Chatman, \& O'Reilly, 1990). Value congruence measures the perceived fit between organizational values and personal values, whereas employee alignment measures employees' levels of trust in the organization and its leaders, in addition to the congruence of values and beliefs (Caldwell et al., 1990). As previously described, Rich et al. (2010) found that value congruence had a significant direct effect on engagement. Rich et al. measured value congruence as the alignment of a worker's values with his or her organization's values. Employee alignment conceptualized with value congruence as an essential facet is expected to produce a similar direct effect on work engagement. Thus, the following hypothesis was tested.

Hypothesis 3: Employee alignment will predict work engagement positively.

The second purpose of the current study is to examine the incremental validity of employee alignment in predicting work engagement. Employee alignment is unique because the construct measures if an individual has confidence in senior leadership as well as the direction the company is headed (Ware, 1999). Employees should be more likely to invest more of themselves into an organization when they believe and value the mission and vision of the senior leadership and the direction that the organization is 
going. In this sense, high levels of employee alignment measure employees' passion and drive towards accomplishing organizational goals because they have confidence in senior leadership and where the company is headed; as a result, they are driven to contribute to the cause. Employee alignment is functional in achieving a company's mission because the workers know that their exertion of effort is focused in the right direction, which creates trust/confidence that they are aligned with company goals and there will be a return on investment of their exertion of personal energies. Employee alignment may show incremental validity above and beyond POS and supportive leader behaviors due to increased perceptions of value congruence, fostering psychological safety due to reduced role ambiguity and confidence in the direction of the organization and its leaders, as well as a sense of meaningfulness.

If employee alignment predicts work engagement above and beyond POS and supportive leader behavior, this might have implications on talent management strategies, organizational development initiatives, and consequently return on investment from the cost of effective recruitment, selection methods, assimilation and onboarding techniques as well as training. However, to the author's best knowledge, no studies have examined the incremental validity of employee alignment in predicting work engagement. Thus, the following research question was posited.

Research question 1: Does employee alignment predict work engagement above and beyond POS and supportive leader behavior? 


\section{Method}

\section{Participants}

The sample consisted of 1,510 business professionals from two industries (software technology and healthcare companies). Data were collected in $2010(n=935)$, $2012(n=365)$, and $2013(n=220)$. Participants ranged in age from 18 to 70 years. The participant pool was a good representation of the three generations in the American workforce between 2010-2013. Baby Boomers (47 - 70 years of age) consisted of $43.8 \%$ of the participants, Generation X (33 - 46 years of age) made up $32.8 \%$ of the sample, and Millennials (18 - 32 years of age) were $23.4 \%$ of the overall participant pool. According to the US Bureau of Labor Statistics (BLS), the projected percentage of age distribution representative of the American workforce for 2011 was that the workforce would consist of $38 \%$ Baby Boomers, followed by $32 \%$ Generation $\mathrm{X}$ and $25 \%$ of Millennials (AARP, 2007). Thus, the sample was distributed similarly according to the BLS national workforce projections. The Baby Boomers generation had a higher percentage due to prior generations being included with the Boomers. The sample consisted predominantly of females $(64.3 \%)$. The sample was diverse in terms of race/ethnicity: White (29.8\%), African American (18.3\%), Hispanic (12.3\%), and Asian $(2.3 \%)$. Thirty six percent of the respondents did not report their race/ethnicity. In sum, a typical participant was a white professional businesswoman (see Table 1). 
Table 1

Demographic Statistics of Participants $(N=1,510)$

\begin{tabular}{llrr}
\hline Variable & & $n$ & $\%$ \\
\hline Gender & & & \\
& Female & 971 & $64.3 \%$ \\
& Male & 539 & $35.7 \%$ \\
& & & \\
& White & 450 & $29.8 \%$ \\
& African American & 276 & $18.3 \%$ \\
& Hispanic or Latino & 186 & $12.3 \%$ \\
& Asian & 34 & $2.3 \%$ \\
& Other & 19 & $1.3 \%$ \\
Industry & Healthcare & & \\
& Technology & 1290 & $85.4 \%$ \\
& 220 & $14.6 \%$ \\
\hline
\end{tabular}

\section{Procedure}

Participants completed an online employee engagement survey. To participate employees had to have worked for the company for at least 60 days. Eligible employees voluntarily participated in the study by utilizing their randomly generate anonymous password to access the online survey. The survey took approximately 15 to 20 minutes to complete, and it had to be completed on-site during business hours in one sitting.

\section{Measures}

The online survey asked peoples' opinions regarding the effectiveness of the organization in the areas of organizational support, managerial support, alignment strategies, and their level of engagement at work and consisted of a total of 23 items (Ware, 1999, 2012). Unless otherwise indicated, the survey utilized a 5-point Likert scale $(1$ = Strongly disagree, 5 = Strongly agree $)$. The scale items were developed based on a literature review and had demonstrated good validity and reliability in the previous 21 years of research conducted by a consulting company in Silicon Valley, California. 
Work engagement. Ware $(1999,2012)$ operationalized work engagement as a psychological state in a work role characterized by a high level of identification with an organization, exhibiting discretionary effort, intent to stay, and alignment to the business goals, mission, and vision. Work engagement measures the constructs of vigor, dedication, and absorption as well as the additional facet of alignment (Schaufeli \& Bakker, 2004; Ware, 1999). Work engagement was measured with six items such as, "I feel motivated to 'go the extra mile'," "I would refer this company to a friend as a good place to work," "I look forward to going to work on most days," "The chances of leaving my job voluntarily during the next year are," and "I am passionate about the work I do here." Employee's responses were summed and averaged to create a composite engagement score. Cronbach's $\alpha$ was .87, indicating high internal consistency of the scale. Higher scores denote higher levels of engagement.

POS. POS was operationalized as the formal policies and procedures as well as the informal corporate culture, which are influential in employees' perceptions of the amount of support provided by their organization. POS was measured by four items such as "This organization provides me with tools I need to help me navigate my career," "The benefits program is good compared to other outside positions for which I am qualified," and "It is easy to find out about other career opportunities that are available for me in this organization." Employee's responses were summed and averaged to create a composite POS score. Cronbach $\alpha$ was .68, indicating adequate reliability of the scale. Higher score indicate higher levels of the perception that the company supported its workers.

Supportive leader behavior. Supportive leader behavior was operationalized as 
the behaviors of managers such as providing support and encouraging a creative team environment. Supportive leader behavior was measured by eight items such as "My manager recognizes me when I do good work," "My manager gives me the right amount of autonomy to do my work successfully," and "My manager solicits my input when making decisions that affect me." Participants' responses were summed and averaged to create a composite supportive leader behavior score. Cronbach $\alpha$ was .92, indicating high internal consistency of the scale. Higher scores among employees indicate higher levels of the perception that managers supported their workers.

Employee alignment. Employee alignment was operationalized as the degree to which workers valued and believed in organizational goals, mission, and vision. Employee alignment was measured by five survey items such as "The company's values are aligned with my personal values," "I am aware of this organization's most critical goals," "I know what is expected of me in my job," and "I feel confident in the direction that this organization is going." Participants' responses were summed and averaged to create a composite employee alignment score. Cronbach $\alpha$ was .73, indicating adequate reliability of the scale. Higher scores among employees indicate higher levels of employee alignment to the mission, vision, and goals of the organization.

Demographic information. Participants were asked to provide demographic information regarding their age, sex, race, and the industry they worked. 


\section{Results}

\section{Descriptive Statistics}

Table 2 shows the descriptive statistics and Pearson correlations of the measured variables. Participants perceived that their organizations supported them moderately $(M$ $=3.58, S D=.85)$, that their managers showed supportive behavior $(M=3.62, S D=.97)$, and their values and goals were aligned with those of their organizations $(M=3.96, S D=$ .73). Participants also reported that they were engaged with their work $(M=3.91, S D=$ $.86)$.

Perceived organizational support $(r=.61, p<.01)$, supportive leader behavior $(r$ $=.59, p<.01)$, and employee alignment $(r=.68, p<.01)$ were all positively and significantly related with work engagement. These results indicate that the more workers perceived that the organization supported and/or valued them, the more employees thought that their managers were supportive, and the more workers' values and beliefs were the same as their organization, the more they were engaged with their work. The correlations among POS, supportive leader behavior, and employee alignment were moderate and positive.

Table 2

Descriptive Statistics and Correlations $(n=1,482)$

\begin{tabular}{lccccc}
\hline \multicolumn{1}{c}{ Variable } & $M$ & $S D$ & 1 & 2 & 3 \\
\hline 1. Perceived organizational support & 3.58 & .85 & & & \\
2. Supportive leader behavior & 3.62 & .97 & $.53 * *$ & & \\
3. Employee alignment & 3.96 & .73 & $.62 * *$ & $.53 * *$ & $.68^{* *}$ \\
4. Work engagement & 3.91 & .86 & $.61 * *$ & $.59 *$ & .60
\end{tabular}

\section{Tests of Hypotheses}


Hypothesis 1 stated that POS would positively predict work engagement.

Hypothesis 2 stated that supportive leader behavior would predict work engagement positively. Hypothesis 3 stated that employee alignment would predict work engagement positively. These hypotheses were tested using a multiple regression analysis. Results are shown in Table 3. Results showed that POS, supportive leader behavior, and employee alignment all together explained $56 \%$ of the variance in work engagement $\left(R^{2}\right.$ $=.56, F(3,1478)=629.09, p<.001)$. POS was found to uniquely contribute to the predictive relationship with work engagement $(\beta=.22, t=9.67, p<.001)$. The more participants perceived that their organization cared or valued them, the more engaged they became with their work. This result supports Hypothesis 1. As expected with Hypothesis 2, supportive leader behavior also uniquely contributed to the predictive relationship with work engagement $(\beta=.26, t=12.27, p<.001)$. Thus, the more participants reported that their managers were supportive, the more engaged they were with their work. This result shows support for Hypothesis 2. Employee alignment uniquely contributed to the predictive relationship with work engagement $(\beta=.40, t=$ $17.30, p<.001)$. In other words, employee alignment predicted employees' work engagement positively. This result shows support for Hypothesis 3.

Table 3

Standard Multiple Regression Analysis Results $(n=1,482)$

\begin{tabular}{|c|c|c|c|}
\hline Variable & $R^{2}$ & $\beta$ & $t$ \\
\hline & $.56^{* * *}$ & & \\
\hline Perceived organizational support & & $.22 * * *$ & 9.67 \\
\hline Supportive leader behavior & & $.26^{* * *}$ & 12.27 \\
\hline Employee alignment & & $.40 * * *$ & 17.30 \\
\hline
\end{tabular}


To summarize, according to the results of the multiple regression analysis, POS, supportive leader behavior, and employee alignment all predicted work engagement. An examination of the beta weights suggests that employee alignment appears to be more important than POS and supportive leader behavior in predicting work engagement.

\section{Research Question}

A research question was posited to examine whether employee alignment would predict work engagement above and beyond POS and supportive leader behavior. A hierarchical multiple regression analysis was utilized to explore this research question. POS and supportive leader behavior were both entered in step one. Employee alignment was entered in step two to test if the variable accounted for more variance in the criterion variable after controlling for the effect of POS and supportive leader behavior. Table 4 demonstrates the results.

The results of the hierarchical multiple regression analysis showed that in step one, POS and supportive leader behavior together accounted for $47 \%$ of the variance in work engagement $\left(R^{2}=.47, F(2,1479)=660.76, p<.001\right)$. POS $(\beta=.37, t=16.80, p<$ $.001)$ and supportive leader behavior $(\beta=.41, t=18.62, p<.001)$ uniquely predicted work engagement. In step two, employee alignment was entered and the total variance explained by the model increased to $56 \%\left(\mathrm{R}^{2}=.56, F(2,1479)=660.76, p<.001\right)$. Employee alignment explained an additional $9 \%$ of variance in work engagement $\left(\Delta \mathrm{R}^{2}=\right.$ $.09, F(1,1478)=299.25, p<.001)$. Therefore, employee alignment significantly predicted employee engagement above and beyond POS and supportive leader behavior. In sum, the research question was supported by the finding that employee alignment 
positively predicted work engagement over and above POS and supportive leader behavior.

Table 4

Hierarchical Regression Analyses $(n=1,482)$

\begin{tabular}{lccccc}
\hline & $R^{2}$ & $\Delta R^{2}$ & $\beta$ & $t$ & partial $r$ \\
\hline Step 1: Perceived organizational support & $.47^{* * *}$ & & $.37^{* * *}$ & 16.80 & .40 \\
Supportive leader behavior & & & $.41^{* * *}$ & 18.62 & .44 \\
Step 2: Employee alignment & $.56^{* * *}$ & $.09^{* * *}$ & $.40^{* * *}$ & 17.30 & .41 \\
\hline
\end{tabular}

*** $\mathrm{p}<.001$, Constant $=.39$

\section{Discussion}

Work engagement has been associated with positive outcomes for both individuals (e.g., increased well-being) and organizations (e.g., profitability) (Hakanen \& Schaufeli, 2012; Kataria, Rastogi, \& Garg, 2013). Due to the positive outcomes associated with work engagement, researchers have paid considerable attention to the identification of factors that predict work engagement. Various job resources (e.g., perceived organizational support, supportive leader behaviors, autonomy) have been shown to predict work engagement. Yet, research attention on personal resources has been relatively scarce. This current study proposed employee alignment, which is defined as the degree to which employees value and believe in the goals, mission, and vision of their organization, as an additional personal resource, and examined it along with the frequently studied job resources of POS and supportive leader behavior as 
predictors of work engagement. Hypothesis 1 stated that POS would positively predict work engagement. Hypothesis 2 stated that supportive leader behavior would predict work engagement positively. Hypothesis 3 stated that employee alignment would predict work engagement positively. The results of the regression analysis indicate support for Hypotheses 1 to 3. These results indicate that POS, supportive leader behavior, and employment alignment all predict work engagement. Consistent with past research, employees' perceptions of support from the organization and its' leaders foster work engagement. Additionally, employees whose values align with the mission and vision of the organization are also more likely to be engaged in their work role.

The present study also posited the research question as to whether employee alignment would show incremental validity in predicting work engagement. The results of the hierarchical regression analysis indicate that employee alignment predicts work engagement over and above POS and supportive leader behavior. When POS and supportive leader behavior were statistically controlled for using hierarchical regression analysis, employee alignment explained the unexplained variance in predicting work engagement. This result indicates that employee alignment has the additive effect of predicting employee engagement above and beyond POS and supportive leader behavior. Therefore, in addition to the perception that the organization supports workers and leaders demonstrate supportive behavior, when workers believe and value the organization's goals, mission, and vision, have confidence and trust in senior leadership and the direction the organization is going, they become engaged in their work role. 
To summarize the results, all hypotheses were supported in terms of the three predictors significantly predicting work engagement, as well as employee alignment showing incremental validity in predicting work engagement above and beyond POS and supportive leader behavior. The following sections discuss theoretical and practical implications of the present findings.

\section{Theoretical Implications of the Present Study}

The study provides additional evidence in support of the JD-R model by producing similar results to previous studies regarding POS and supportive leader behavior predicting work engagement. Job resources such as POS and supportive leader behaviors are likely to increase work engagement as well as have a reciprocal causality effect with the personal resource of employee alignment (Xanthopoulou et al., 2009).

Employee alignment as a personal resource adds to the theoretical framework of the antecedents of work engagement. Past research has mainly focused on personality traits as personal resources, but the results of this study demonstrated that an attitude-like variable, employment alignment, could be considered a personal resource that predicts work engagement. In other words, employee alignment could be considered a new factor to increase work engagement among employees. The construct taps into the beliefs and attitudes of workers toward their organization and their leaders. This finding extends the JD-R model by adding a personal resource of employee alignment as a predictor of work engagement. The theoretical implication of employee alignment is by harnessing, perpetuating, and/or creating workers' positive attitudes and beliefs this should increase their personal investment of time and energy into their work role. 
According to Fredrickson (2001), the broaden-and-build theory posits that positive emotions seem to benefit people's thoughts and actions, and through this broadening process, people could constantly build upon these positive emotions. If a worker's positive attitude and beliefs (employee alignment) lead to work engagement and positive organizational outcomes, they may lead to increased personal resources such as selfefficacy and positive affect (Salanova, Llorens, \& Schaufeli, 2011; Xanthopulou et al., 2009).

\section{Practical Implications of the Present Study}

The results of the present study suggest various ways to increase an engaged workforce. For example, organizational development initiatives such as strategies to increase perceptions of organizational support through the implementation of a job rotation program, provide leaders with professional development, and promote employee alignment; all of which should foster engagement as well as employees' trust.

Based on the finding that POS positively predicts work engagement, organizations could increase POS through offering competitive remuneration packages and providing the tools needed for employees to navigate their career. Organizations could create a culture of learning and development through job rotation programs, which identify and utilize their workforces' strengths as well as provide cross training to employees in preparation for their next career move within the company. Lastly, companies could utilize industry compensation benchmarks to base their remuneration packages to increase the attraction of the organization to prospective employees. In addition, benefits targeting the demographic of the prospective talent that the competitors 
do not offer may give organizations a competitive edge in attraction such as charity involvement.

With respect to the finding that supportive leader behavior predicts work engagement, there are many organizational practices that could improve supportive leader behaviors. Supportive leader behavior emphasizes the important role managers play in creating a work environment that fosters trust and engagement. The key management behaviors found to increase engagement in this study were providing autonomy, demonstrating democratic leadership behaviors (soliciting input from workers on decisions that affect them), and giving recognition to their subordinates. These behaviors emphasize the importance of regular two-way communication, recognition, and feedback; in other words, an increased frequency of constructive supervisor interactions may increase work engagement. A supportive leader provides feedback and helps workers learn from their mistakes. Coaching may also increase self-efficacy of workers, which has been shown to be a strong determinant of increased performance through work engagement (Salanova et al., 2011; Xanthopulou et al., 2009; Xanthopoulou, Bakker, Heuven, Demerouti, \& Schaufeli, 2008). Thus, the priority of effective coaching should be to increase communication, recognition, and feedback, which in turn predict work engagement.

One of the practical implications based on the finding that employee alignment positively predicts work engagement, organizations might develop talent management strategies that impact employee alignment throughout the entire employee lifecycle: recruitment, selection, development, and retention. Employee alignment techniques are 
an integral facet of strategic talent management for organizations. Employee alignment could start with recruitment because this is the first point of contact with the organization for many potential employees. A company statement clearly indicting the mission and values of the organization is important in attracting the talent that shares the same values as the organization. The next step of an effective employee alignment strategy would be a selection process that assesses the degree to which the prospective employees' values align with those of the organization through an interview process that may include structured interviews, a self-report assessment, and a behavioral assessment. For example, a situational interview question to assess employee alignment would be "Why do you want to work for this company?" and "What are your personal work goals and purpose for the future?"

In addition to recruitment and selection techniques, organizations should work on a strategy that employees internalize organizational values and beliefs as their own (at a minimal level employees are aware of organizational mission, vision, values, and beliefs). Companies should create environments that communicate and promote value congruence between employees and the organization such as designing formal onboarding and socialization programs to facilitate aligning of values. These orientation programs are likely to be effective in influencing employees (particularly the new hires). These strategies have a component similar to organizational socialization, which assists in delineating the situational self or "work self," based on social identity theory (Ashforth $\&$ Mael, 1989). The benefit for the company of aligning workers' personal and organizational values and goals is to increase the perception of P-O fit; as a result, 
increased vigor, dedication, and absorption by workers in their work role is likely to occur. For example, the researcher asserts that employees are typically most motivated and engaged when they are starting in a new company. Strategies that increase employee alignment such as onboarding techniques that socialize the new hires into the corporate culture and assure how their role contributes to organizational success are likely to harness employees' positive psychological state (i.e., work engagement).

Furthermore, when recruitment, selection, and orientation are consistent with aligning workers during the assimilation process, executive level leaders could communicate the importance of the mission and vision, which strengthens the message to employees (particularly the new hires), and this message should be further reinforced by all leaders through recognition and feedback when employees exhibit these behaviors consistent with the mission and vision of the organization (Christian et al., 2011). Another measure to emphasize employee alignment is that all training and development be aligned to the organization's mission, vision, and values by linking the training back to the core values throughout training and upon completion. In other words, to increase employee alignment, companies should use compelling messaging through multiple methods that communicate and reinforce the organization's mission, vision, goals, and values, and this should be done throughout the entire employee life cycle starting at recruitment, selection, and development in order to assimilate, engage, and retain employees.

To summarize the implications of the research investigating the key drivers of work engagement for the entire workforce, organizations can increase POS through 
creating a culture of development by rolling out a job rotation program, increase the perception of supportive leader behavior through coaching, and increase employee alignment through strategies to synchronize workers with organizational mission, vision, and goals.

\section{Strengths, Limitations, and Future Research}

A strength of the study was that a large sample size enabled statistical power to detect actual effect. The limitation of the current study is the findings were based on the American national sample and diminish the generalizability of the findings to work environments globally. Therefore, these findings based on an individualistic culture may not all apply to work environments particularly in collectivistic cultures (Hofstede, 2001). Future research could include international participants in collectivistic cultures in order to increase the generalizability of the findings. Another limitation was the sample was based on two industries with the majority being from healthcare. Future research could collect data from participants from a wide variety of industries to increase the generalizability fo the findings.

Future research should be directed at examining whether the construct of employee alignment displays discriminant validity from similar constructs such as value congruence and P-O fit. The discriminant validity study would be beneficial in determining if employee alignment and value congruence or P-O fit are measuring the same phenomenon and are therefore redundant.

Future research should also be directed at investigating employee alignment in terms of its relationship with personal resources such as self-efficacy and the reciprocal 
causality model of engagement (Salanova, Llorens, \& Schaufeli, 2011; Xanthopulou et al., 2009). Employee alignment may be related to the upward gain spiral of personal resources with self-efficacy/self-esteem via goal achievement in the reciprocal causality model (Bakker \& Bal, 2010; Xanthopulou et al., 2009).

Research should be done regarding the alignment of values and a new hire entering the organization (Macey \& Schneider, 2008). More specifically, research could investigate the level of congruence between employees and the organization at various stages in the employee lifecycle to determine if this influences their overall engagement. For example, if a worker's values are not initially aligned to the organization, does this mean they will not be as engaged as other workers or are workers malleable in terms of alignment and engagement?

Future supportive leader behavior research could examine which particular leader behaviors develop trust and ultimately foster engagement. The concept of trust appears to be the underlying phenomenon mediating the relationship between the predictors of work engagement and work engagement. Leader behavior in particular seems to exhibit the most influence on workers' engagement levels due to daily contact and the fact that employees base their perceptions of the organization on the leaders they report directly to. Thus, research should focus on studying what leader behavior fosters managerial trustworthiness since leaders are so influential in employees' daily levels of engagement (Whitener, Brodt, Korsgaard, \& Werner, 1998).

\section{Conclusion}


Work engagement produces many benefits for both individuals (e.g., life satisfaction, organizational commitment) and organizations (e.g., increased financial results). Work engagement focuses on the whole psychological state of the employee and the interaction of job demands and resources on energy toward role performance, identification with their work, and absorption in their work role. Results of the present study show that employee alignment is an additional predictor of work engagement and has additive predictive validity above and beyond POS and supportive leader behaviors. Organizations that are able to create a safe/trusting work environment characterized by POS and supportive leader behavior as well as having workers whose values are aligned to the mission, vision, and values of the company are more likely to have a competitive advantage due to an engaged workforce that displays discretionary effort and organizational identification. Results of the present study have many practical implications to increase work engagement among employees. 


\section{References}

AARP, 2007. Leading a Multigenerational Workforce, Retrieved on February 17, 2014 from: http://assets.aarp.org/www.aarp.org/articles/money/employers/leading multigenerational workforce.pdf.

Ashforth, B. E., \& Mael, F. (1989). Social identity theory and the organization. Academy of Management Review, 14(1), 20-39. doi:10.5465/AMR.1989.4278999

Bakker, A. B. (2011). An evidence-based model of work engagement. Current Directions in Psychological Science, 20(4), 265-269. doi:10.1177/0963721411414534

Bakker, A. B., \& Bal, P. M. (2010). Weekly work engagement and performance: A study among starting teachers. Journal of Occupational \& Organizational Psychology, 83(1), $189-206$.

Bakker, A.B., \& Demerouti, E. (2007). The job demands-resources model: State of the art. Journal of Managerial Psychology, 22, 309-328.

Bakker, A.B., \& Demerouti, E. (2008). Towards a model of work engagement. Career Development International, 13, 209-223.

Bakker, A.B., Van Emmerik, I.J.H, \& Euwema, M.C. (2006). Crossover of burnout and engagement in work teams. Work and Occupations, 33, 464-489.

Bakker, A. B., \& Xanthopoulou, D. (2009). The crossover of daily work engagement: Test of an actor-partner interdependence model. Journal of Applied Psychology, 94(6), 1562-1571.

Bargagliotti, L. A. (2012). Work engagement in nursing: A concept analysis. Journal of Advanced Nursing, 68(6), 1414-1428. doi:10.1111/j.1365-2648.2011.05859.x

Caldwell, D. F., Chatman, J. A., \& O'Reilly, C. A. (1990). Building organizational commitment: A multi-firm study. Journal of Occupational \& Organizational Psychology, 63: 245-251.

Chalofsky, N., \& Krishna, V. (2009). Meaningfulness, commitment, and engagement: The intersection of a deeper level of intrinsic motivation. Advances in Developing HumanResources, 11(2), 189-203.

Christian, M., Garza, A., \& Slaughter, J., (2011). Work engagement: a quantitative review and test of its relations with task and contextual performance. Personnel Psychology, 64, 89136. 
Deci, E. L., Connell, J. P., \& Ryan, R. M. (1989). Self-determination in a work organization. Journal of Applied Psychology, 74(4), 580.

Edmondson, A. (1999). Psychological safety and learning behavior in work teams. Administrative Science Quarterly, 44(2), 350-383.

Eisenberger, R., Stinglhamber, F., Vandenberghe, C., Sucharski, I. L., \& Rhoades, L. (2002). Perceived supervisor support: Contributions to perceived organizational support and employee retention. Journal of Applied Psychology, 87(3), 565573. doi:10.1037/0021 9010.87.3.565

Fairlie, P. (2011). Meaningful work, employee engagement, and other key employee outcomes:Implications for human resource development. Advances in Developing Human Resources, 13(4), 508-525. doi:10.1177/1523422311431679

Fredrickson, B.L. (2001). The role of positive emotions in positive psychology: The broaden- and-build theory of positive emotions. American Psychologist, 56, 218226.

Freeney, Y., \& Fellenz, M. R. (2013). Work engagement, job design and the role of the social context at work: Exploring antecedents from a relational perspective. Human Relations, $\quad$ 66(11), 1427-1445. doi:10.1177/0018726713478245

Hakanen, J. J., \& Schaufeli, W. B. (2012). Do burnout and work engagement predict depressive symptoms and life satisfaction? A three-wave seven-year prospective study. Journal of Affective Disorders, 141(2-3), 415-424.

doi:10.1016/j.jad.2012.02.043

Halbesleben, J. R. B. (2010). A meta-analysis of work engagement: Relationships with burnout, demands, resources, and consequences. In A. B. Bakker \& M.P. Leiter (Work engagement: A handbook of essential theory and research), (102-117). New York, NY US: Psychology Press.

Havens, D. S., Warshawsky, N.E. \& Vasey, J. (2013). RN work engagement in generational cohorts: the view from rural US hospitals. Journal of Nursing Management, 21, 927-940.

Hobfoll, S.E., Johnson, R.J., Ennis, N., \& Jackson, A.P. (2003). Resource loss, resource gain, and emotional outcomes among inner city women. Journal of Personality and Social Psychology, 84, 632-643.

Hofstede, G. (1984). Culture's consequences: Comparing values, behaviors, institutions, and organizations across nations, Thousand Oaks, CA: Sage. 
Kahn, W.A. (1990). Psychological conditions of personal engagement and disengagement at work. Academy of Management Journal, 33, 692-724.

Kast, F.E. \& Rosenzweig, J.E. (1979). Organization and management, New York: McGraw-Hill.

Kataria, A., Rastogi, R., \& Garg, P. (2013). Organizational effectiveness as a function of employee engagement. South Asian Journal of Management, 20(4), 56-73.

Kottke, J. L., \& Sharafinski, C. E. (1988). Measuring perceived supervisory and organizational support. Educational and Psychological Measurement, 48, 1075-1079.

Lorente, L.R., Salanova, M.S., Martinez, I.M. \& Schaufeli, W.B. (2008). Extension of the job demands-resources model in the prediction of burnout and engagement among teachers over time, Psicothema, 20,354-360.

Luthans, F., Norman, S.M., Avolio, B.J., \& Avey, J.B. (2008). The mediating role of psychological capital in the supportive organizational climate-employee performance relationship. Journal of Organizational Behavior, 29, 219-239.

Macey, W. H., \& Schneider, B. (2008). The meaning of employee engagement. Industrial \& Organizational Psychology, 1(1), 3-30. doi:10.1111/j.1754-9434.2007.0002.x

Mauno, S., Kinnunen, U., Mäkikangas, A., \& Feldt, T. (2010). Job demands and resources as antecedents of work engagement: A qualitative review and directions for future research. In S. L. Albrecht (Handbook of employee engagement), (111-128). Northampton, MA US: Edward Elgar Publishing.

May, D. R., Gilson, R. L., \& Harter, L. M. (2004). The psychological conditions of meaningfulness, safety and availability and the engagement of the human spirit at work. Journal of Occupational \& Organizational Psychology, 77(1), 11-37.

Oldham, G. R., \& Cummings, A. (1996). Employee creativity: Personal and contextual factors at work. Academy of Management Journal, 39(3), 607-634. doi:10.2307/256657

Rhoades, L., \& Eisenberger, R. (2002). Perceived organizational support: A review of the literature. Journal of Applied Psychology, 87(4), 698-714.

Roberts, D.R., \& Davenport, T.O. (2002). Job engagement: Why it's important and how to $\quad$ improve it. Employment Relations Today, 29(3),21-29. 
Rich, B.L., Lepine, J.A., \& Crawford, E.R. (2010). Job engagement: antecedents and effects on job performance. Academy of Management Journal, 53(3), 617-635.

Saks, A.M. (2006). Antecedents and consequences of employee engagement. Journal of Managerial Psychology, 21, 600-619.

Schaufeli, W.B., \& Bakker, A.B. (2004). Job demands, job resources, and their relationship with burnout and engagement: A multi-sample study. Journal of Organizational Behavior, 25, 293-315.

Schneider, B., Macey, W. H., Barbera, K. M., \& Martin, N. (2009). Driving customer satisfaction and financial success through employee engagement. People \& Strategy, $\quad 32(2), 22-27$.

Shore, L. M., \& Tetrick, L. E. (1991). A construct validity study of the survey of perceived organizational support. Journal of Applied Psychology, 76, 637-643.

Shuck, B., Reio, T. G., \& Rocco, T. S. (2011). Employee engagement: An examination of antecedent and outcome variables. Human Resource Development International, 14(4), 427-445. doi:10.1080/13678868.2011.601587

Spreitzer, G. M., Kizilos, M. A., \& Nason, S. W. (1997). A dimensional analysis of the relationship between psychological empowerment and effectiveness, satisfaction, and strain. Journal of Management, 23, 679-704.

US Bureau of Labor Statistics, 2013, Women in the Labor Force: A Data Book, BLS Reports, report 1040. Retrieved on February 26, 2014 from: http://www.bls.gov/cps/wlf-databook2012.pdf

Ware, B.L. (1999). Integral talent systems employee engagement survey manager tool kit (Eds.)

Ware, B.L. (2012). Integral talent systems employee engagement survey manager tool kit (Eds.)

Wildermuth, C., \& Pauken, P.D., (2008). A perfect match: decoding employee engagement - Part I: Engaging cultures and leaders. Industrial and Commercial Training, 40(3), 122128.

Vassos, M., Nankervis, K., Skerry, T., \& Lante, K. (2013). Work engagement and job burnout within the disability support worker population. Research in Developmental Disabilities, 34(11), 3884-3895. doi:10.1016/j.ridd.2013.08.005 
Xanthopoulou, D., Bakker, A.B., Demerouti, E., \& Schaufeli, W.B. (2007). The role of personal resources in the job demands-resources model. International Journal of Stress Management, 14, 121-141.

Xanthopoulou, D., Bakker, A.B., Demerouti, E., \& Schaufeli, W.B. (2009). Work engagement and financial returns: A diary study on the role of job and personal resources. Journal of Occupational and Organizational Psychology, 82, 183-200.

Xanthopoulou, D., Baker, A. B., Heuven, E., Demerouti, E., \& Schaufeli, W. B. (2008). Working in the sky: A diary study on work engagement among flight attendants. Journal of Occupational Health Psychology, 13(4), 345-356. doi:10.1037/10768998.13.4.345 